\title{
Autism in Toddlers Born Very Preterm
}

Margo Anne Pritchard, PhD, ${ }^{a}$ Therese de Dassel, MPsych(Clin), ${ }^{b, c}$ Elaine Beller, PhD, ${ }^{d}$ Fiona Bogossian, PhD, ${ }^{c}$ Linda Johnston, PhD, ${ }^{e}$ Jessica Paynter, PhD, ${ }^{f}$ Santo Russo, PhD, ${ }^{8}$ James Scott, MDa,c

OBJEctive: This study aimed to determine the prevalence of autism spectrum disorder (ASD) by using the Autism Diagnostic Observation Schedule-Generic (ADOS-G) classifications in children born very preterm during their toddler years.

METHODS: Two birth cohorts of toddlers ( 2 and 4 years old) each recruited over 12 months and born at $<29$ weeks' gestation were administered the Modified Checklist of Autism in Toddlers-Follow-up Interview (M-CHAT-FI) screen, the ADOS-G, and developmental assessments. The ADOS-G was conducted on toddlers with M-CHAT-FI-positive screens. RESULtS: Data were available on 88\% (169/192) of children. In total, 22 (13\%) toddlers screened positive and $3(1.8 \%)$ were confirmed diagnostically with ASD. These 3 cases reached the highest ADOS-G threshold classification of autism. All but 1 child who scored below the ADOS-G thresholds (11/12) demonstrated some difficulty with social communication. Risk was significantly increased for co-occurring neurodevelopmental problems in 21 of the 22 positive-screen ASD cases. Adaptive behavior $(P<.001)$ was the only co-occurring factor independently predictive of ASD in toddlers.

CONcLusions: Children born very preterm are at increased risk of ASD. By using the ADOS-G, we found a lower incidence of ASD in children born at $<29$ weeks' gestation compared with previous studies. Children who screened positive for ASD on the M-CHAT-FI had developmental delays consistent with subthreshold communication impairment.

\begin{abstract}
${ }^{a}$ Australian Catholic University, Brisbane, Queensland, Australia; ${ }^{b}$ Royal Brisbane Women's Hospital, Brisbane, Queensland, Australia; 'BBond University, Robina, Queensland, Australia; ${ }^{d} T$ The University of Queensland, Brisbane, Queensland, Australia; ${ }^{e}$ University of Toronto, Toronto, Ontario, Canada; ${ }^{f}$ Autism Early Intervention and Ootcome Unit Foundation, Brisbane, Queensland, Australia; ${ }^{g}$ Better Life Psychology, Brisbane, Queensland, Australia

Dr Pritchard conceptualized and designed the study, applied for/received funding, coordinated and supervised recruitment and data collection, and drafted the initial manuscript; Ms de Dassel designed the study, conducted neurodevelopmental assessments, and drafted the initial manuscript; Dr Beller designed the study, carried out the initial analyses, and reviewed and revised the manuscript; Drs Bogossian and Johnston designed the study, applied for/received funding, and drafted the initial manuscript; Mr Russo designed the study, conducted the ADOS assessments, and drafted the initial manuscript; Dr Paynter drafted the initial manuscript; Dr Scott reviewed the outcomes of all cases and drafted the initial manuscript; and all authors approved the final manuscript as submitted and agree to be accountable for all aspects of the work.
\end{abstract}

DOI: $10.1542 /$ peds.2015-1949

Accepted for publication Nov 16, 2015

Address correspondence to Margo Anne Pritchard, PhD, Australian Catholic University, Aubigny Place, Raymond Terrace, South Brisbane QId 4101, Queensland, Australia. E-mail: margo.

pritchard@acu.edu.au

PEDIATRICS (ISSN Numbers: Print, 0031-4005; Online, 1098-4275).

Copyright (C) 2016 by the American Academy of Pediatrics

FINANCIAL DISCLOSURE: The authors have indicated they have no financial relationships relevant to this article to disclose.
WHAT'S KNOWN ON THIS SUBJECT: Diagnostic estimates of autism in children born prematurely by using the only semistructured observational assessment Autism Diagnostic Observation Schedule-General are scarce.

WHAT THIS STUDY ADDS: This study provides further support of elevated rates of autistic disorder and an associated subthreshold social communication profile in children born <29 weeks' gestation; using the Autism Diagnostic Observation Schedule-General, our prevalence of $1.8 \%$ is lower than previously reported.

To cite: Pritchard MA, de Dassel T, Beller E, et al. Autism in Toddlers Born Very Preterm. Pediatrics. 2016;137(2):e20151949 
Autism spectrum disorders (ASDs) are a heterogeneous group of developmental disorders evident in early childhood and are characterized by qualitative impairments in communication, social relations, and repetitive and restricted behaviors and interests. When considering the global burden of disease, ASDs are the leading cause of disability in children $<5$ years of age. ${ }^{1,2}$ The diagnostic prevalence of disorders within the spectrum is reported to be higher in those born extremely ${ }^{3,4}$ and very preterm ${ }^{5-9}$ (3.6\%-12.9\%) compared with the general population prevalence $(\sim 1 \%) .{ }^{10}$ The rates for ASD are reported to be highest in 2-year-olds $(12.9 \%)^{7}$ and similar in children $(3.6 \%-8 \%)^{4,6,8}$ and adults $(5 \%)^{5}$ born prematurely. The most commonly reported diagnostic classification within the spectrum in these studies is the narrowly defined autistic disorder (Diagnostic and Statistical Manual of Mental Disorders, Fourth Edition $)^{11}$ or childhood autism (International Classification of Diseases, 10th Revision). ${ }^{12}$ High rates of co-occurring severe neonatal brain abnormalities and neurosensory and cognitive impairments also have been reported in children born preterm with ASD and are speculated to be implicated in the expression of the behaviors displayed. ${ }^{3,4,6}$ These impairments also are associated with the high positive screen rates reported in the preterm population. ${ }^{5,8,13-16}$ Although these screening studies overestimate diagnostic outcome, children born preterm often demonstrate a profile of early social communication and emotional difficulties consistent with ASD characteristics. ${ }^{4,14}$

The variability in the rates of ASD in these studies is likely influenced by the eligibility of the preterm population, age assessed, loss to follow-up, and the specific assessment tool used.
All of the diagnostic studies reporting the prevalence of ASD in schoolaged children used semistructured diagnostic interview assessment tools. 3,4,6,8,9 Two studies used the direct semistructured observational assessment called the Autism Diagnostic Observation ScheduleGeneric (ADOS-G) in toddlers ${ }^{7}$ or in combination with the Autism Diagnostic Interview-Revised ${ }^{17}$ in adults. ${ }^{5} \mathrm{~A}$ recent systematic review assessing the accuracy of diagnostic tools with the gold standard (multidisciplinary team assessments with consensus clinical judgment) diagnosis showed that the ADOS most reliably meets the threshold for clinical accuracy, ${ }^{18}$ which is further improved when children are assessed within the context of a neurodevelopmental clinic. ${ }^{19}$ In view of these reports, and the paucity of diagnostic studies using the ADOS-G, our primary aim was to determine the prevalence of ASD in the context of routine developmental follow-up for toddlers born very preterm. All children were screened by using the Modified Checklist of Autism in Toddlers-Follow-up Interview (M-CHAT-FI) and positive cases were diagnostically assessed using the ADOS-G. Secondarily, we examined the subthreshold autistic traits, and neonatal, family, and developmental characteristics associated with positive screening.

\section{METHODS}

The cohort comprised all infant survivors with their estimated date of confinement falling in 2006 and 2008, in children born at $<29$ weeks' gestational age (GA), who received tertiary-level neonatal care at the Royal Brisbane and Women's Hospital, Australia. Participants enrolled in the study were assessed at 2 and 4 years' corrected age in conjunction with their routine developmental follow-up assessment in 2010. The study was approved by the institutional Human Research Ethics Committees. Parental informed written consent was required for participation.

\section{Assessments and Measures}

Autism Study Assessments

Autism study assessments included the $\mathrm{M}-\mathrm{CHAT},{ }^{20}$ which is a parentcompleted 23-item yes/no screening tool for ASD. A positive ASD screen requires the child to be positive on any 3 items or any 2 of 6 critical items. Items that screened positive are further systematically probed with the FI. The FI follows a script that asks for specific examples of behaviors and offers multiple examples against which to judge whether the child passed or failed the item. The FI is reported to substantially improve the M-CHAT's positive predictive value in the 2 -year-old (from 0.36 to 0.74 ) and in the 4-year-old (from 0.38 to 0.59 ) general pediatric population. ${ }^{21}$ Children who screened M-CHAT-FI positive were assessed for ASD by an experienced educational psychologist trained in using the ADOS-G. ${ }^{22}$ The ADOS-G is the only tool that provides a semistructured direct assessment of the child's social and communication skills and behavior. It comprises 4 modules based on verbal skills and is designed for use across age ranges from 2 years to adulthood. In this study, Module 1 (for children who do not consistently use phrased speech) and Module 2 (for children who use phrased speech but who are not verbally fluent) were used. Children with profound intellectual or motor disabilities fall below the floor of the measure and cannot be reliably assessed. Scoring is based on observations of the child's behavior and items are scored for the communication and social interaction domains as well as for stereotypical behaviors and restricted interests, including play and imaginative use of materials. Each item is scored from 0 (no abnormality) to 2 or 3 (moderate 
to severe abnormality). Scores are placed into a diagnostic algorithm that gives separate domain scores for communication (range 0-10) and reciprocal social interaction (range 0 -14), and a communication + social interaction total (range 0-24). Cutoff scores for both communication and reciprocal social interaction and their sum (Module 1: autism cutoff $=12$; autism spectrum = 7; Module 2: autism = 12; autism spectrum $=8$ ) are used to classify ASD as autism (highest cutoff score) and autism spectrum (lower cutoff score with fewer symptoms). The neurodevelopmental team evaluated all cases in the context of the child's overall developmental assessment for potential misclassification.

\section{Developmental Follow-up Assessment}

Developmental follow-up assessment was routinely conducted on all children by a neurodevelopmental team blinded to the child's history. Children were assessed for cerebral palsy, which included a neurologic examination and motor assessment, ${ }^{23,24}$ and for impairments in vision, visual acuity $<6 / 60$, and hearing, requiring aids. Cognitive and language ability were assessedby using the Bayley Scales of Infant and Toddler Development, Third Edition ${ }^{25}$ cognitive and language composite indices and the Wechsler Preschool and Primary Scale of Intelligence-Third Edition (Australian), ${ }^{26}$ Full-Scale IQ, and the Verbal IQ scores, in the 2- and 4-year-old children, respectively. Adaptive behavior was assessed by using the Adaptive Behavior Assessment System-Second Edition General Adaptive Composite score. ${ }^{27}$ Cognitive, language, and adaptive behavior were classified relative to the tests' norms (mean $=100$; $\mathrm{SD}=$ 15) for all assessments except the Bayley Scales of Infant and Toddler Development, Third Edition, in which Australian term-born reference data were used (Cognition, mean = 108.9; $\mathrm{SD}=14.3$; Language, mean $=108.2 ; \mathrm{SD}=14.8){ }^{28}$ Scores $<-2$ SDs were classified as moderate-severe delay. We used the corresponding domains on the Parents' Evaluation of Developmental Status: Developmental MilestonesAssessment Level (PEDS:DM-AL) 29,30 to assess cognition, language, and adaptive behavior in children who did not return for psychometric assessment. A score of $\geq 25 \%$ of skills not mastered in a domain is classified as delayed and demonstrates sound screening test characteristics (sensitivity 74\%, specificity 83\%) in children born preterm. ${ }^{31}$

\section{Psychosocial and Neonatal Risks}

Psychosocial and neonatal risks were assessed by using the Brigance Observations of Psychosocial Risk Scale $^{32}$ and those with $\geq 4$ of 11 risk factors present were classified as having high psychosocial risk in accordance with the scoring manual. Assessments of neonatal factors were collected from patient records, and coded according to Australian and New Zealand Neonatal Network data definitions. ${ }^{33}$ This is a collaborative network of all Australian and New Zealand Neonatal Intensive Care Units that uses standardized data definitions for monitoring the care of high-risk newborn infants.

\section{Data Analysis}

Descriptive statistics were used to illustrate the prevalence of the ADOS-G and M-CHAT-FI classified ASD and the baseline, neonatal, and developmental characteristics by M-CHAT-FI screening status and the ADOS-G profile of the M-CHAT-FI positive screen children in the combined cohort. Univariable and multivariable analyses were used to examine which social, neonatal, and developmental factors were associated with the M-CHAT-FI.

Analysis was adjusted for psychosocial risk, child gender, age, and profound disabled cases. The criterion for statistical significance for multivariable analysis was set at a 2-tailed value of .01 to control for family-wise error. Data are presented as means or percentages, odds ratios (ORs) with 95\% confidence intervals (CIs), and $P$ values for the combined cohort. Data were analyzed by using Statistical Package Social Sciences for Windows (version 22.0; IBM SPSS Statistics, IBM Corporation, Chicago, IL).

\section{RESULTS}

Of the 192 surviving children, 169 (88\%) participated in the study, 13 were lost to follow-up, and 10 parents refused their child's participation. All participants completed the M-CHAT-FI and developmental follow-up assessments, 153 children completed the psychometric tests, and the remaining 16 children completed the PEDS:DM-AL (Fig 1). The baseline characteristics of the children in the study group (Table 1) and those not studied were comparable in terms of baseline, maternal, and neonatal characteristics.

\section{Prevalence of Screening ASD}

In total, 13\% (22 of 169) of children screened positive for ASD by using the M-CHAT-FI. Nine (40.9\%) of the 22 children failed $\geq 2$ critical items, with the remainder failing any 3 items. Positive screening results (2 years $13.6 \%$ and 4 years $12 \%$ ) and failing critical items ( 2 years, $n=$ 4 of $11,37 \%$; and 4 years, $n=5$ of $11,45 \%$ ) were similar for both age groups.

\section{Clinical Characteristics and Their Relationship to First-Stage Screen Results}

Univariable analyses are shown in Table 1. Multivariable analysis showed that only adaptive behavior was independently associated with M-CHAT-FI positive results (OR 15.0, 95\% CI 5.7-43.4, $P<.001$ ), even after adjusting for psychosocial risk, gender, age, and profound disabled cases (OR 9.9, 95\% CI 3.4-28.7, $P<$ 
TABLE 1 M -CHAT-FI Screening Status for ASD by Baseline, Neonatal, and Developmental Factors in 169 Children

\begin{tabular}{|c|c|c|c|c|}
\hline Factors & M-CHAT-FI Positive, $n=22$ & M-CHAT-FI Negative, $n=147$ & OR $(95 \% \mathrm{Cl})$ & $P$ \\
\hline \multicolumn{5}{|l|}{ Baseline } \\
\hline GA, wk, mean $( \pm S D)$ & $26.7(1.4)$ & $26.6(1.4)$ & & .74 \\
\hline $\mathrm{GA} \leq 26$ & $8(36)$ & $69(45)$ & $0.7(0.3-1.6)$ & .35 \\
\hline Boys & $15(68)$ & $79(53)$ & $1.8(0.7-4.8)$ & .20 \\
\hline Maternal age $\geq 35$ & $4(18)$ & $27(18)$ & $1.0(0.3-3.4)$ & .98 \\
\hline Plurality & $4(18)$ & $46(31)$ & $0.5(0.2-1.5)$ & .32 \\
\hline Psychosocial risk & $5(22)$ & $19(13)$ & $1.9(0.7-5.9)$ & .21 \\
\hline \multicolumn{5}{|l|}{ Neonatal } \\
\hline Retinopathy of prematurity $\geq 3$ or laser therapy & $3(13)$ & $20(13)$ & $1.0(0.3-3.7)$ & .97 \\
\hline $\begin{array}{l}\text { Bronchopulmonary dysplasia, late-onset sepsis, or } \\
\text { necrotizing enterocolitis }\end{array}$ & $14(63)$ & $83(56)$ & $1.4(0.5-3.4)$ & .53 \\
\hline $\begin{array}{l}\text { Interventricular hemorrhage } \geq 3 \text {, cystic formation, or } \\
\text { hydrocephalus }\end{array}$ & $3(13)$ & $17(11)$ & $1.2(0.3-4.5)$ & .72 \\
\hline No breastfeeding on discharge & $10(45)$ & $34(23)$ & $2.8(1.1-6.9)$ & .04 \\
\hline \multicolumn{5}{|l|}{ Development } \\
\hline Cerebral palsy & $8(36)$ & $15(10)$ & $5.0(1.8-13.9)$ & .01 \\
\hline Vision or hearing impairment & $2(9)$ & $3(6)$ & $3.4(0.9,12.0)$ & .07 \\
\hline Cognitive delay $<-2$ SD & $11(50)$ & $19(13)$ & $6.7(2.5-17.6)$ & $<.001$ \\
\hline Language delay $<-2$ SD & $12(54)$ & $23(15)$ & $6.4(2.5-16.5)$ & $<.001$ \\
\hline Adaptive behavior delay $<-2$ SD & $15(68)$ & $20(13)$ & $13.6(4.9-47.4)$ & $<.001$ \\
\hline Any atypical development & $21(95)$ & $42(28)$ & $52.5(6.8-400)$ & $<.001$ \\
\hline
\end{tabular}

All values are $n$ (\%) unless otherwise noted. OR indicates the OR for having a positive screen, given the presence of the factor. Atypical development indicates any cerebral palsy, blindvision, or hearing impairment, or cognitive, language, or adaptive behavior delay.

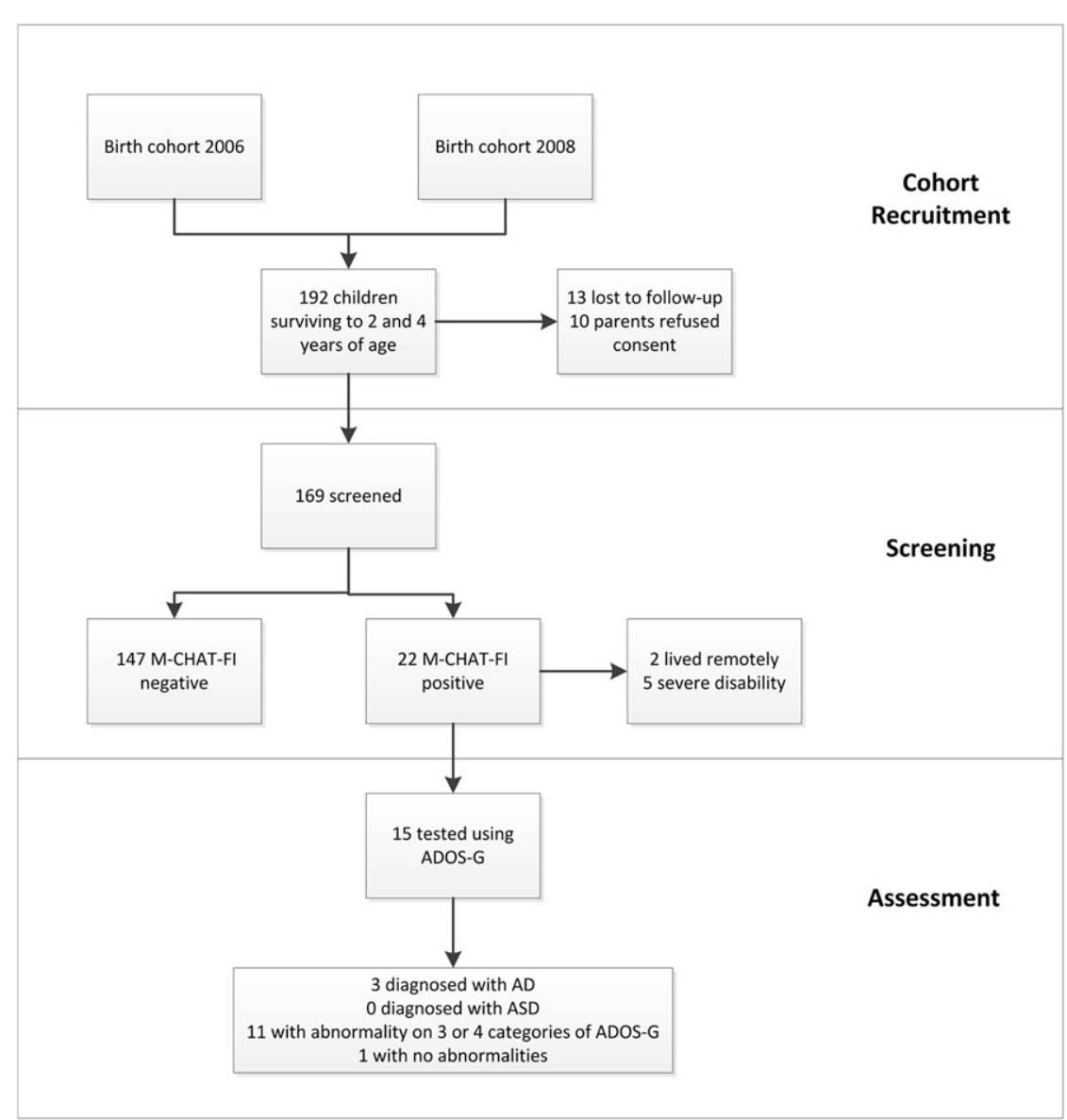

FIGURE 1

Recruitment, screening, and assessment flow sheet of the birth cohorts.
.001). When we removed adaptive behavior from the multivariable analysis, language delay independently predicted the positive M-CHAT-FI screen (OR 4.3, 95\% CI 1.5-14.7, $P<.001)$. No pattern of distribution of positive M-CHAT-FI children by GA was identified.

\section{Prevalence of Diagnostic ASD}

Of the 22 M-CHAT-FI positive screens eligible for ADOS-G assessment, 2 of the 2-year-old children lived remotely and were unable to return to the clinic; 1 of these had mild cerebral palsy and the other had a mild cognitive delay. Five children had severe-profound disability and could not be reliably assessed. Fifteen children ( 2 years, $n=7$ and 4 years, $n=8$ ) were assessed by using the ADOS-G. Four children were assessed using Module 1 and 11 were assessed using Module 2. The ADOS-G classified $1.8 \%$ (3 of 169) of cases with ASD with all cases meeting criteria for autism (the highest cutoff), which included two 2-year-olds and one 4-year-old child. No children were classified in the autism spectrum range (the lower cutoff score). Two children had 


\begin{tabular}{|c|c|c|c|c|}
\hline \multirow[t]{3}{*}{ ADOS-G Domains and Items } & \multicolumn{2}{|c|}{ ADOS-G Classification Subclinical, Item Score $=1$} & \multicolumn{2}{|c|}{ AD0S-G Classification Clinical, Item Score $>1$} \\
\hline & $\begin{array}{l}\text { ADOS-G Positives, } \\
\quad n=3\end{array}$ & AD0S-G Negatives, $n=12$ & $\begin{array}{l}\text { ADOS-G Positives, } \\
\quad n=3\end{array}$ & ADOS-G Negatives. $n=12$ \\
\hline & $n(\%)$ & $n(\%)$ & $n(\%)$ & $n(\%)$ \\
\hline \multicolumn{5}{|l|}{ Communication domain items } \\
\hline $\begin{array}{l}\text { Amount of social overtures/maintenance of attention } \\
\text { *Frequency of vocalization directed to others }\end{array}$ & 0 & $8(67)$ & $3(100)$ & 0 \\
\hline Stereotyped/idiosyncratic use of words or phrases & $1(33)$ & 0 & $1(33)$ & 0 \\
\hline Conversation. *Use of other's body to communicate & 0 & $6(50)$ & $1(33)$ & 0 \\
\hline Pointing & $1(33)$ & $3(25)$ & $2(66)$ & 0 \\
\hline $\begin{array}{l}\text { Descriptive, conventional, instrumental, or informational } \\
\text { gestures }\end{array}$ & $2(66)$ & $6(50)$ & $1(33)$ & 0 \\
\hline \multicolumn{5}{|l|}{ Reciprocal social interaction } \\
\hline Unusual eye contact & 0 & 0 & $2(66)$ & 0 \\
\hline Facial expressions directed to others & $2(66)$ & $1(8)$ & 0 & 0 \\
\hline Spontaneous initiation of joint attention & $3(100)$ & $1(8)$ & 0 & 0 \\
\hline $\begin{array}{l}\text { Quality of social overtures } \\
\text { *Showing }\end{array}$ & $2(66)$ & $4(33)$ & $1(33)$ & 0 \\
\hline $\begin{array}{l}\text { Quality of social response } \\
\text { *Shared enjoyment in interaction }\end{array}$ & 0 & $3(25)$ & $2(66)$ & 0 \\
\hline $\begin{array}{l}\text { Amount of reciprocal social communication. *Response to } \\
\text { joint attention }\end{array}$ & 0 & $5(42)$ & $3(100)$ & 0 \\
\hline $\begin{array}{l}\text { Overall quality of rapport } \\
{ }^{*} \text { Quality of social overtures }\end{array}$ & $1(33)$ & $2(17)$ & $1(33)$ & 0 \\
\hline \multicolumn{5}{|l|}{ Stereotypical behavior and restricted interest } \\
\hline Unusual sensory interest in play material/person & $1(33)$ & $1(8)$ & 0 & 0 \\
\hline Hand and finger and other complex mannerisms & $1(33)$ & 0 & 0 & 0 \\
\hline Unusually repetitive interests or stereotyped behavior & 0 & $3(25)$ & 0 & 0 \\
\hline Imagination/creativity. *Play with objects & 0 & $4(33)$ & $2(66)$ & $1(8)$ \\
\hline
\end{tabular}

Module 2 items are stated in this table. Module 1 items are indicated by an asterisk.

Module $1 n=4$, Module $2 n=11$.

significantly reduced imagination and play and 2 were observed to have some stereotypical behavior and restricted interest. All 3 children had a co-occurring neurodevelopmental problem (Supplemental Table 3). No misclassified cases were identified.

\section{ADOS-G Domain and Item Profiles of the Children Categorized Nonspectrum}

Eleven of the 12 children categorized as ADOS-G negative or nonspectrum scored some level of abnormality on $\geq 2$ of the 4 domain categories on the ADOS-G assessment (Supplemental Table 3). One-third of these children reached the Communication domain lower cutoff threshold for ASD and had delayed cognition or language ability. Additionally, onethird of children had stereotypical behavior or restricted interests and more than one-third (5/12) showed reduced imaginative play or appropriate play with objects. All but 1 child experienced $\geq 1$ co-occurring neurodevelopmental problems. The ADOS-G scores in each domain suggested a subthreshold social communication impairment in the ADOS-G negative children (Supplemental Table 3).

There were wide-ranging developmental delays in ADOS-G communication and social reciprocal interaction domain item scores in the M-CHAT-FI positive screen children. Most children who were ADOS-G negative did have mild communication impairment (item scores of 1), indicating these children were showing less of the communication behaviors than would be expected for their age (Table 2).

\section{DISCUSSION}

The current study sought to investigate the prevalence of ASD in toddlers born at $<29$ weeks' GA by using a 2-stage procedure, within a developmental follow-up program, whereby positive M-CHAT-FI-screened children were diagnostically assessed by using the ADOS-G. Previous research using diagnostic assessment tools found an elevated risk of ASD across ages in children born preterm of between $3.6 \%$ and $12.9 \%$, relative to term controls or general population prevalence $<1 \%$. $3,4,7$ The diagnostic prevalence in the current study of $1.8 \%$ was composed exclusively of children meeting the cutoff for autism. However, compared with the general population, the elevated prevalence of the more narrowly 
defined autism was consistent with previous studies of ASD in the preterm population in both toddlers and older children. ${ }^{3,4,7}$ Our lower prevalence may have been an effect of the ADOS-G, which is less sensitive to lower compared with higher threshold scores. ${ }^{18}$

The only other diagnostic study in toddlers is by Dudova et al, ${ }^{7}$ who used the ADOS-G, and who found prevalence in 2-year-old children with birth weight $<1500 \mathrm{~g}$ and without major disability that was 7 times greater than our prevalence. Potential explanations for this discrepancy are the high loss to follow-up ( $>40 \%$ ) and potential rating bias in the previous study. Furthermore, the Dudova et $\mathrm{al}^{34}$ study used birth weight rather than GA as the inclusion criteria and relied on clinical judgment of cognitive and motor development, which may have led to important differences in the sample under investigation. Unlike our study, Dudova $^{7}$ applied a concept of best-estimate clinical diagnosis, by consensus of 2 experienced specialists, and reported 1 misclassified ADOS-G-positive case. In our study, we reviewed all screening and diagnostic cases in the overall context of their developmental assessments and found no misclassified cases. As we found no autism spectrum cases (lower threshold scores), it is possible that we missed higherfunctioning ASD cases. The study by Pinto-Martin et $\mathrm{al}^{5}$ used the ADOS-G and Autism Diagnostic Interview-Revised and found 2.5\% of nonspectrum adults met the ADOS-G criteria at the lowerthreshold autism spectrum and had higher intelligence scores compared with the screen-positive cases. It is likely that the method of determining misclassified cases will affect estimates. Further research investigating all cases and the links between developmental functioning, birth weight, GA, and ASD is needed to elucidate the mechanism or mechanisms that lead to an elevated rate and classification differences within ASD in children born preterm.

Previous research with the preterm population also has reported high positive screening rates for ASD. The M-CHAT is the most frequent ASD screen reported in the preterm toddler population and has consistently yielded high screening rates $(21 \%-41 \%)$ even when adjusted for disability (10\%-16.5\%). With the introduction of the FI for positive M-CHAT screens, the rate in both late ${ }^{35}$ and very ${ }^{36}$ preterm toddlers has recently been reported at $2.4 \%$ and $3.1 \%$, respectively. Our rate of $13 \%$, although predictably lower than those reports using the M-CHAT without the FI, was more than 4 times higher than that reported in studies using the FI. ${ }^{35,36}$ Our rate of positive screens adjusted for co-occurring disability was $3.6 \%$ and similar to that reported by the studies using the M-CHAT-FI. ${ }^{35,36}$ We may have been less restrictive in our use of the FI, and although we report a higher screening rate, we also describe the false-positive screens with subthreshold communication impairment. We anticipate that some of these children may be later diagnosed with ASD.

It is unclear if the use of multiple screening tests improves accurate identification of ASD in the preterm population. In older-aged cohorts, the use of multiple ${ }^{5}$ compared with single ${ }^{4}$ screens yields similar screening rates between $18.3 \%$ and $15.8 \%$ and diagnostic prevalence rates between $5 \%$ and $8 \%$. In toddlers born preterm, the use of multiple screens has yielded high but varied positive rates $(20 \%-$ $35.7 \%$ on any screen; $1 \%-9 \%$ on all screens). ${ }^{7,37,38}$ Only 1 study, by Dudova et al, ${ }^{38}$ used diagnostic validation for combinations of screens and demonstrated sensitivity and specificity $>76 \%$ in all combinations except when all 3 screen tests had to be positive, which yielded a sensitivity of $23 \%$.

It is not clear how the associated impaired development in children born preterm contributes to the development of ASD. Like other studies, ${ }^{6,39}$ we demonstrated a significantly increased rate of cerebral palsy and cognition and language delay in the M-CHAT-FIpositive toddlers. Language delay was the only delay that predicted positive ASD screens; however, when we included adaptive behavior, it showed the strongest predictor of screen-positive cases. This is not surprising, as communication and social skills deficits are both characteristics of ASD and pivotal aspects of adaptive behavior. Importantly though, a subthreshold social communication profile was very common in the ADOS-G nonspectrum children who screened M-CHAT-FI positive. This profile has been shown repeatedly in other studies $4,15,16$ suggesting false-positive children may meet the criteria for the new category of Social Communication Disorder by using Diagnostic and Statistical Manual of Mental Disorders, Fifth Edition criteria. ${ }^{40}$ Developmental surveillance of this subthreshold group may also be of assistance in monitoring whether these children later meet diagnostic criteria as further symptoms manifest when social demands exceed capacities. Continued surveillance of this cohort is ongoing and recently conducted longitudinal assessment may reveal additional cases.

The current study was limited through using the ADOS-G Module 1 or 2 . Since the time of data collection for these studies, a revised form that 
includes a toddler module has been developed that may be more sensitive to this age and ability range. ${ }^{41}$ Furthermore, the absence of control cases may limit comparisons to other groups. Emerging research suggests a developmental surveillance approach that begins earlier in infancy may be more sensitive to identification of ASD in young children. ${ }^{42}$ Testing the applicability of this approach to children born preterm would be an important area for further research. Nevertheless, the current 2-stage approach is likely to be a feasible approach to identifying young children at risk for ASD in clinical practice.

\section{CONCLUSIONS}

This study provides further support of elevated rates of autistic disorder and an associated subthreshold social communication profile in the preterm population, although our data suggest rates may not be as high as previously reported. Further research is needed to understand the mechanisms leading to an elevated prevalence of ASD in the preterm population. The current study highlights the need for assessment of ASD in children born preterm because of the heightened risk that symptoms may be overlooked due to the range of other developmental problems.

\section{ABBREVIATIONS}

ADOS-G: Autism Diagnostic Observation

Schedule-Generic

ASD: autism spectrum disorder

CI: confidence interval

GA: gestational age

M-CHAT-FI: Modified Checklist of Autism in ToddlersFollow-up Interview

OR: odds ratio

PEDS:DM-AL: Parents' Evaluation of Developmental Status:

Developmental MilestonesAssessment Level

FUNDING: Funded by a Royal Brisbane and Women's Hospital Foundation Grant.

POTENTIAL CONFLICT OF INTEREST: The authors have indicated they have no potential conflicts of interest to disclose.

\section{REFERENCES}

1. Baxter AJ, Brugha TS, Erskine HE, Scheurer RW, Vos T, Scott JG. The epidemiology and global burden of autism spectrum disorders. Psychol Med. 2015;45(3):601-613

2. Gardener H, Spiegelman D, Buka SL. Perinatal and neonatal risk factors for autism: a comprehensive meta-analysis. Pediatrics. 2011;128(2):344-355

3. Hack M, Taylor HG, Schluchter M, Andreias L, Drotar D, Klein N. Behavioral outcomes of extremely low birth weight children at age 8 years. J Dev Behav Pediatr. 2009;30(2):122-130

4. Johnson S, Hollis C, Kochhar P, Hennessy E, Wolke D, Marlow N. Autism spectrum disorders in extremely preterm children. J Pediatr. 2010;156(4):525-31.e2

5. Pinto-Martin JA, Levy SE, Feldman JF, Lorenz JM, Paneth N, Whitaker AH. Prevalence of autism spectrum disorder in adolescents born weighing <2000 grams. Pediatrics. 2011;128(5):883-891

6. Treyvaud K, Ure A, Doyle LW, et al. Psychiatric outcomes at age seven for very preterm children: rates and predictors. J Child Psychol Psychiatry. 2013;54(7):772-779
7. Dudova I, Kasparova M, Markova D, et al. Screening for autism in preterm children with extremely low and very low birth weight. Neuropsychiatr Dis Treat. 2014;10:277-282

8. Indredavik MS, Vik T, Heyerdahl S, Kulseng S, Fayers P, Brubakk AM. Psychiatric symptoms and disorders in adolescents with low birth weight. Arch Dis Child Fetal Neonatal Ed. 2004;89(5):F445-F450

9. Elgen I, Sommerfelt K, Markestad T. Population based, controlled study of behavioural problems and psychiatric disorders in low birthweight children at 11 years of age. Arch Dis Child Fetal Neonatal Ed. 2002;87 (2):F128-F132

10. Developmental Disabilities Monitoring Network Surveillance Year 2010 Principal Investigators; Centers for Disease Control and Prevention (CDC). Prevalence of autism spectrum disorder among children aged 8 years-autism and developmental disabilities monitoring network, 11 sites, United States, 2010. MMWR Surveill Summ. 2014;63(2):1-21

11. American Psychiatric Association. Diagnostic and Statistical Manual of Mental Disorders: DSM-IV. Washington,
DC: American Psychiatric Association; 1994

12. World Health Organization. International Classification of Diseases, 10th Revision (ICD-10) Geneva, Switzerland: WHO; 2011

13. Moore T, Johnson S, Hennessy E, Marlow N. Screening for autism in extremely preterm infants: problems in interpretation. Dev Med Child Neurol. 2012;54(6):514-520

14. Limperopoulos C, Bassan H, Sullivan $\mathrm{NR}$, et al. Positive screening for autism in ex-preterm infants: prevalence and risk factors. Pediatrics. 2008;121(4):758-765

15. Kuban KC, O'Shea TM, Allred EN, Tager-Flusberg H, Goldstein DJ, Leviton A. Positive screening on the Modified Checklist for Autism in Toddlers (M-CHAT) in extremely low gestational age newborns. J Pediatr. 2009;154(4):535-540.e1

16. Wong HS, Huertas-Ceballos A, Cowan FM, Modi N; Medicines for Neonates Investigator Group. Evaluation of early childhood social-communication difficulties in children born preterm using the Quantitative Checklist for Autism in Toddlers. J Pediatr. 2014;164(1):26-33.e1 
17. Rutter M, Le Couteur A, Lord C. ADI-R. Autism Diagnostic Interview Revised Manual. Los Angeles, CA: Western Psychological Services; 2003

18. Falkmer T, Anderson K, Falkmer M, Horlin C. Diagnostic procedures in autism spectrum disorders: a systematic literature review. Eur Child Adolesc Psychiatry. 2013;22(6):329-340

19. Carter SE, Hanson A, Bravey C, Al Kabir N. How to use... an autism assessment tool. Arch Dis Child Educ Pract Ed. 2013:98(2):58-63

20. Robins DL, Fein D, Barton ML, Green JA. The Modified Checklist for Autism in Toddlers: an initial study investigating the early detection of autism and pervasive developmental disorders. J Autism Dev Disord. 2001;31(2):131-144

21. Kleinman JM, Robins DL, Ventola $\mathrm{PE}$, et al. The modified checklist for autism in toddlers: a follow-up study investigating the early detection of autism spectrum disorders. J Autism Dev Disord. 2008;38(5):827-839

22. Lord C, Risi S, Lambrecht L, et al. The Autism Diagnostic Observation Schedule-Generic: a standard measure of social and communication deficits associated with the spectrum of autism. J Autism Dev Disord. 2000;30(3):205-223

23. Amiel-Tison C, Stewart A. Follow up studies during the first five years of life: a pervasive assessment of neurological function. Arch Dis Child. 1989:64 (spec no. 4):496-502

24. Palisano R, Rosenbaum P, Walter S, Russell D, Wood E, Galuppi B. Development and reliability of a system to classify gross motor function in children with cerebral palsy. Dev Med Child Neurol. 1997;39(4):214-223

25. Bayley N. Bayley Scales of Infant and Toddler Development. 3rd ed. San Antonio, TX: Harcourt Assessment; 2006

26. Wechsler D. Wechsler Preschool and Primary Scale of Intelligence, Third Edition (WPPSI-III Australia)
Administration and Scoring Manual. Sydney, New South Wales, Australia: Psychological Corporation; 2004

27. Harrison PL, Oakland T. Adaptive Behavior Assessment System - Second Edition (ABAS-II). San Antonio, Texas, United States of America: Psychological Corporation; 2003

28. Anderson PJ, De Luca CR, Hutchinson E, Roberts G, Doyle LW; Victorian Infant Collaborative Group. Underestimation of developmental delay by the new Bayley-III Scale. Arch Pediatr Adolesc Med. 2010;164(4):352-356

29. Brothers KB, Glascoe FP, Robertshaw NS. PEDS: developmental milestonesan accurate brief tool for surveillance and screening. Clin Pediatr (Phila). 2008;47(3):271-279

30. Gascoe FP, Robertshaw NS. Using the PEDS: DM Assessment Level. Parents' Evaluation of Developmental Status Developmental Milestones (PEDS: DM) - Professionals' Manual: A Tool for Surveillance and Screening. Melbourne, Victoria, Australia: Hawker Brownlow Education; 2007

31. Pritchard M, de Dassel T, Beller E, et al. Parents' Evaluation of Developmental Status (PEDS: DM) and the Parenting Relationship in Children Born Very Preterm. The 4th Congress of the European Academy of Paediatric Societies (EAPS). Istanbul, Turkey: EAP; 2012

32. Glascoe FP. Brigance Observations of Psychosocial Risk Scale. Collaborating With Parents: Using Parents' Evaluation of Developmental Status (PEDS) to Detect and Address Developmental and Behavioral Problems. Nashville, TN: Ellsworth \& Vandermeer Press LLC; 2002

33. Australian and New Zealand Neonatal Network. Data Dictionary. Sydney, New South Wales, Australia: University of New South Wales; 2013

34. Hrdlicka M, Dudova I. Screening preterm children for autism at 2 years of age. J Pediatr. 2015;167(1):212
35. Guy A, Seaton SE, Boyle EM, et al. Infants born late/moderately preterm are at increased risk for a positive autism screen at 2 years of age. $J$ Pediatr. 2015;166(2):269-275.e3

36. Gray PH, Edwards DM, O'Callaghan MJ, Gibbons K. Screening for autism spectrum disorder in very preterm infants during early childhood. Early Hum Dev. 2015;91(4):271-276

37. Stephens BE, Bann CM, Watson VE, et al; Eunice Kennedy Shriver Nationa Institute of Child Health and Human Development Neonatal Research Network. Screening for autism spectrum disorders in extremely preterm infants. J Dev Behav Pediatr. 2012;33(7):535-541

38. Dudova I, Markova D, Kasparova M, et al. Comparison of three screening tests for autism in preterm children with birth weights less than 1,500 grams. Neuropsychiatr Dis Treat. 2014;10:2201-2208

39. Johnson S, Hollis C, Kochhar P, Hennessy E, Wolke D, Marlow N. Psychiatric disorders in extremely preterm children: Iongitudinal finding at age 11 years in the EPICure study. $\checkmark$ Am Acad Child Adolesc Psychiatry. 2010;49(5):453-463.e1

40. American Psychiatric Association. Diagnostic and Statistical Manual of Mental Disorders: DSM-5. Washington, DC: American Psychiatric Association; 2013

41. Luyster R, Gotham K, Guthrie W, et al. The Autism Diagnostic Observation Schedule-toddler module: a new module of a standardized diagnostic measure for autism spectrum disorders. J Autism Dev Disord. 2009;39(9):1305-1320

42. Barbaro J, Dissanayake C. Prospective identification of autism spectrum disorders in infancy and toddlerhood using developmental surveillance: the social attention and communication study. J Dev Behav Pediatr. 2010;31(5):376-385 


\section{Autism in Toddlers Born Very Preterm}

Margo Anne Pritchard, Therese de Dassel, Elaine Beller, Fiona Bogossian, Linda Johnston, Jessica Paynter, Santo Russo and James Scott

Pediatrics 2016;137;

DOI: 10.1542/peds.2015-1949 originally published online January 21, 2016;

\section{Updated Information \& Services}

Supplementary Material

References

Subspecialty Collections

Permissions \& Licensing

Reprints including high resolution figures, can be found at:

http://pediatrics.aappublications.org/content/137/2/e20151949

Supplementary material can be found at:

http://pediatrics.aappublications.org/content/suppl/2016/01/20/peds.2

015-1949.DCSupplemental

This article cites 30 articles, 6 of which you can access for free at: http://pediatrics.aappublications.org/content/137/2/e20151949.full\#re f-list-1

This article, along with others on similar topics, appears in the following collection(s):

\section{Developmental/Behavioral Pediatrics}

http://classic.pediatrics.aappublications.org/cgi/collection/developme nt:behavioral_issues_sub

Autism/ASD

http://classic.pediatrics.aappublications.org/cgi/collection/autism:asd sub

Cognition/Language/Learning Disorders

http://classic.pediatrics.aappublications.org/cgi/collection/cognition:1 anguage:learning_disorders_sub

Information about reproducing this article in parts (figures, tables) or in its entirety can be found online at:

https://shop.aap.org/licensing-permissions/

Information about ordering reprints can be found online: http://classic.pediatrics.aappublications.org/content/reprints

Pediatrics is the official journal of the American Academy of Pediatrics. A monthly publication, it has been published continuously since. Pediatrics is owned, published, and trademarked by the American Academy of Pediatrics, 141 Northwest Point Boulevard, Elk Grove Village, Illinois, 60007. Copyright @ 2016 by the American Academy of Pediatrics. All rights reserved. Print ISSN:

\section{American Academy of Pediatrics}

DEDICATED TO THE HEALTH OF ALL CHILDREN ${ }^{\mathrm{m}}$ 


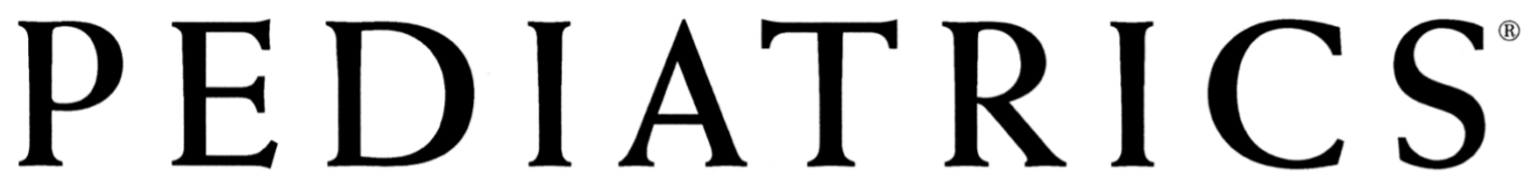

OFFICIAL JOURNAL OF THE AMERICAN ACADEMY OF PEDIATRICS

\section{Autism in Toddlers Born Very Preterm}

Margo Anne Pritchard, Therese de Dassel, Elaine Beller, Fiona Bogossian, Linda

Johnston, Jessica Paynter, Santo Russo and James Scott

Pediatrics 2016;137;

DOI: 10.1542/peds.2015-1949 originally published online January 21, 2016;

The online version of this article, along with updated information and services, is located on the World Wide Web at:

http://pediatrics.aappublications.org/content/137/2/e20151949

Pediatrics is the official journal of the American Academy of Pediatrics. A monthly publication, it has been published continuously since. Pediatrics is owned, published, and trademarked by the American Academy of Pediatrics, 141 Northwest Point Boulevard, Elk Grove Village, Illinois, 60007. Copyright @ 2016 by the American Academy of Pediatrics. All rights reserved. Print ISSN:

\section{American Academy of Pediatrics}

DEDICATED TO THE HEALTH OF ALL CHILDREN ${ }^{m}$ 